\title{
IL-33 signaling is essential to attenuate viral-induced encephalitis development by downregulating iNOS expression in the central nervous system
}

Rafael F. O. Franca ${ }^{1 *+}$, Renata S. Costa ${ }^{2 \dagger}$, Jaqueline R. Silva², Raphael S. Peres ${ }^{2}$, Leila R. Mendonça', David F. Colón ${ }^{2}$, José Carlos Alves-Filho ${ }^{3}$ and Fernando Q. Cunha ${ }^{3^{*}}$

\begin{abstract}
Background: Viral encephalitis is a common cause of lethal infections in humans, and several different viruses are documented to be responsible. Rocio virus is a flavivirus that causes a severe lethal encephalitis syndrome in humans and also mice, providing an interesting model to study the CNS compartmentalized immune response. Interleukin 33 (IL-33), a member of the IL-1 family, is an immunomodulatory cytokine that is highly expressed in the CNS. However, the role of IL-33 on viral encephalitis remains unclear. Therefore, we aimed to explore how the IL-33/ST2 axis regulates the local immune response during Rocio virus infection.
\end{abstract}

Methods: Wild-type (WT), ST2 (ST2 ${ }^{-1-}$ ), and nitric oxide synthase-deficient mice (iNOS ${ }^{-1-}$ ) and Stat6 $\left(\right.$ Stat6 $\left.^{-1-}\right)$-deficient mice were infected with different concentrations of the Rocio virus by intraperitoneal route, the cytokine mRNA level in CNS was analyzed by qPCR, and cellular immunophenotyping was performed on infected mice by the flow cytometry of isolated CNS mononuclear cells.

Results: We have shown that the mRNA expression of IL-33 and ST2 receptors is increased in the CNS of Rocio virus-infected WT mice and that ST2 ${ }^{-/-}$mice showed increased susceptibility to infection. ST2 deficiency was correlated with increased tissue pathology, cellular infiltration, and tumor necrosis factor alpha (TNF-a) and interferon-gamma (IFN-y) mRNA levels and higher viral load in the CNS, compared with wild-type mice. The increased Th1 cytokine levels released in the CNS acted on infiltrating macrophages, as evidenced by flow cytometry characterization of cellular infiltrates, inducing the expression of iNOS, contributing to brain injury. Moreover, iNOS ${ }^{-1-}$ mice were more resistant to Rocio virus encephalitis, presenting a lower clinical score and reduced mortality rate, despite the increased tissue pathology.

Conclusions: We provide evidences of a specific role for IL-33 receptor signaling in nitric oxide induction through local IFN- $\gamma$ modulation, suggesting that nitric oxide overproduction might have an important role in the progression of experimental viral encephalitis.

Keywords: Interleukin 33, ST2 receptor, Experimental viral encephalitis, Nitric oxide, Flavivirus

\footnotetext{
*Correspondence: rafael.franca@cpqam.fiocruz.br; fdqcunha@fmrp.uspbr

${ }^{\dagger}$ Equal contributors

'Department of Virology and Experimental Therapy LAVITE, Oswaldo Cruz

Foundation - FIOCRUZ, Institute Aggeu Magalhães IAM, Av. Professor Moraes

Rego, s/n, Recife, PE 50740-465, Brazil

${ }^{3}$ Department of Pharmacology, Ribeirão Preto School of Medicine, University

of São Paulo, Ribeirão Preto, SP 14049-900, Brazil

Full list of author information is available at the end of the article
} 


\section{Background}

The Rocio virus (ROCV), member of the Flaviviridae family with some well-known viruses, such as West Nile, dengue, yellow fever, and more recently Zika, is a singlestranded RNA virus that infects humans and other vertebrates. Infection with $\mathrm{ROCV}$ leads to a wide range of symptoms including, but not restrict to, the following: fever, headache, anorexia, nausea, vomiting, myalgia, and malaise. The pathology of this viral infection in humans ranges from asymptomatic to acute encephalitis [1]. Previous studies from our group demonstrated that ROCV infects and induces in $\mathrm{BALB} / \mathrm{c}$ mice damage of the central nervous system (CNS), characterized by neuronal degeneration and apoptosis with detectable levels of inflammatory cytokines and massive cellular infiltration [2]. Moreover, cellular infiltration in CNS is highly dependent of the CCR-5/MIP- $1 \alpha$ axis, since CCR5 and macrophage inflammatory protein 1 alpha (MIP-1 $\alpha$ ) knockout mice presented reduced inflammation with increased survival rates after ROCV infection [3]. CNS cellular infiltration induced by ROCV infection is characterized by $\mathrm{F} 4 / 80^{+}$ cells, detected early as 4 days post-infection. At later points after infection, the CNS became infiltrated with NK, B cells, and especially $\mathrm{T}$ lymphocytes. Locally, these cells produce high amounts of interferon-gamma (IFN- $\gamma$ ) and tumor necrosis factor alpha (TNF- $\alpha$ ), among other cytokines, which contribute to the degeneration and death of neurons with extensive tissue damage [2].

Interleukin 33 (IL-33), a member of the IL-1 cytokine family, is constitutively expressed by tissue barrier cells such as the epithelial and endothelial cells of different body compartments. In addition, some innate immune cells such as macrophages and dendritic cells also express IL-33 [4-6]. IL-33 is recognized as the functional ST2 receptor ligand, a heterodimer receptor complex consisting of ST2 and the IL-1 receptor accessory protein (IL-1RAcP) [4]. ST2 cell surface expression is observed on T helper 2 (Th2) cells but not on $\mathrm{T}$ helper (Th1) cells; thus, it functions as an important effector molecule of T helper type 2 responses [7]. ST2 activation signals through the myeloid differentiation primary response gene 88 (MyD88) and nuclear factor kappa b (NF$\mathrm{kB}$ ) pathway, inducing the production of several cytokines and chemokines. Moreover, ST2 activation causes cell differentiation, polarization, and activation, depending on the target cell [5].

On viral and parasitic experimental infections, IL-33 plays a crucial role in the local immune response to several different pathogens [8-11]. In fact, it has been reported that in mice, IL-33 is necessary for effective cluster of differentiation $8\left(\mathrm{CD}^{+}\right) \mathrm{T}$ cell responses to replicate lymphocytic choriomeningitis virus (LCMV), an RNA virus, and against murine $\gamma$-herpesvirus 68 (MHV-68), a DNA virus. Interestingly, recombinant IL-33 administration improved vaccine-induced $\mathrm{CD}^{+} \mathrm{T}$ cell responses to vaccinia virus-based vectors and virus-like particles (VLPs) [12]. Following infection with coxsackievirus $B(C V B)$, mice deficient for T1/ST2 (IL-33R signaling) significantly developed more severe pancreatitis with greater weight loss and higher viral load compared with wild type [8]. However, the role of IL-33 in the ROCVinduced host CNS-damage was not addressed yet. In human, rhinovirus infection induced asthma exacerbation dependent of IL-33 and the production of type 2 cytokines IL-4, IL-5, and IL-13. The authors state that IL-33 induction directly correlates with viral load and IL-5 and IL-13 levels, proposing IL-33 inhibition as a novel therapeutic approach for virus-induced asthma exacerbations [13]. However, depending on the organ involved and the Th1/ Th2 immune balance necessary to control the infection, IL-33 may also present opposing roles.

Herein, we are showing that the ST2 receptor is expressed in the CNS during experimental murine ROCVinduced encephalitis. The ST2 deficiency, by target disruption in BALB/c mice $\left(\mathrm{T} 1 / \mathrm{ST}^{-/-}\right)$, led to impaired control of viral burden in the CNS, which was associated with an early cellular CNS infiltration and a Th1-polarized immune response with consequent increased expression of the cytokines TNF- $\alpha$ and IFN- $\gamma$, which in turn upregulates tissue inducible nitric oxide synthase (iNOS) expression. In the brain, the generation of reactive nitrogen species through iNOS induction could act by increasing the oxidative stress responsible for tissue injury, worsening the disease. In conclusion, our data suggest that IL-33 might play a crucial role in the pathogenesis of virusinduced encephalitis by controlling the local Th1/Th2 balance.

\section{Results}

\section{BALB/c mice are susceptible to ROCV infection}

First, we assessed the susceptibility of BALB/c by infecting these animals with different concentrations of the Rocio virus (ROCV) by intraperitoneal (i.p.) route. By 9 days after i.p. inoculation, $1.10^{6}$ plaqueforming unit (PFU) ROCV-infected mice experienced $100 \%$ mortality; in contrast, $1.10^{5}$ PFU ROCVinfected mice showed a reduced and delayed mortality. The peak of mortality was $70 \%$ which was reached at 11 days post-infection (Fig. 1a). There are no differences on weight change on mice infected with $1.10^{6}$ or $1.10^{5}$ PFU (Fig. 1b); however, higher titer-infected mice displayed an earlier development of encephalitis signals, as determined by clinical score (Fig. 1c). We also recovered increased tissue virus concentrations on higher titer-infected mice, since this group presented a higher viral load on the brain, when compared to low titer infection (Fig. 1d). 


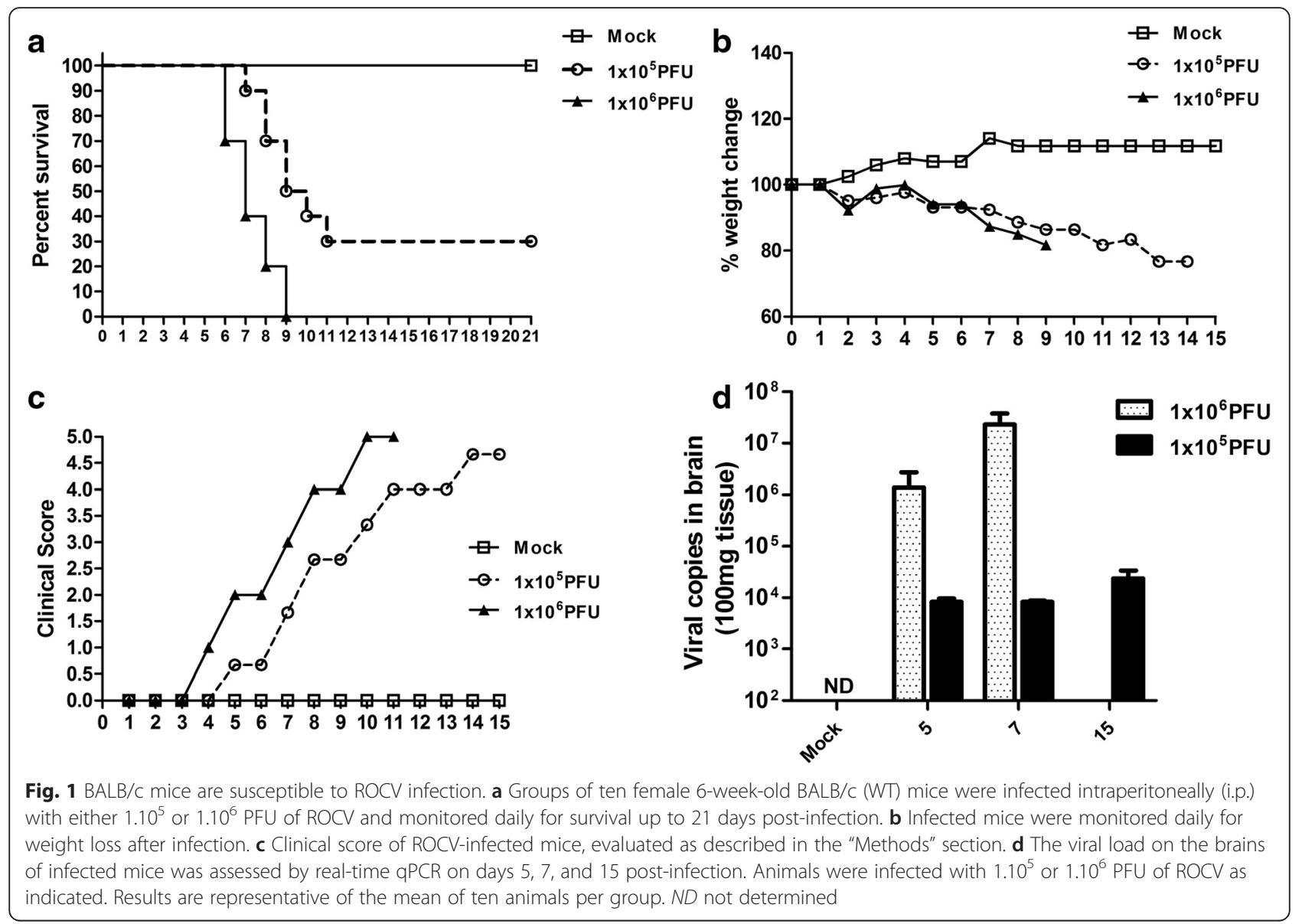

Infected BALB/c mice display high cell infiltration and cytokine production in the CNS

In two previous studies, we characterized partially the immune response to ROCV infection [2, 3]. Here, to better understand the immunopathologic process, we infected BALB/c mice with $1.10^{6} \mathrm{PFU}$ ROCV, sacrificed these animals at 5 and 7 days post-infection (p.i.) (when encephalitis symptoms are evident) and analyzed the profile of cell infiltration in the CNS by fluorescentactivated cell sorting (FACS). We observed an increased cellular infiltration on CNS, characterized mainly by $\mathrm{CD}^{-}$cells at 5 and 7 days p.i. (Fig. 2a). In the cellular infiltrates, it was also demonstrated the presence of $\mathrm{CD}^{+}$cells (Fig. 2b), constituted in its majority by $\mathrm{CD}^{+} \mathrm{CD}^{+}$cells and fewer $\mathrm{CD}^{+} \mathrm{CD}^{+}$cells, and these infiltrates were significantly higher at 7 days p.i., coinciding with disease peak and clinical symptom appearance (Fig. 2c). Next, we analyzed the kinetics of the local immune response by quantifying the messenger ribonucleic acid (mRNA) expression level of $\mathrm{T}$ helper subtype signature cytokines IFN- $\gamma$ and IL-17A and the proinflammatory cytokine TNF- $\alpha$, in the CNS of ROCVinfected mice. The TNF- $\alpha$ mRNA level was significantly increased at 5 days p.i., reaching an even higher level by
7 days p.i. (Fig. 2d). At 7 days p.i., we observed a massive expression of IFN- $\gamma$ mRNA (Fig. 2e), coinciding with the appearance of $\mathrm{CD}^{+}$on the CNS tissue (Fig. 2b, c) and signs of disease. As expected, the IL-17A cytokine (Fig. 2f) was not significantly altered on ROCV-infected animals, when compared to mock-infected animals.

\section{IL-33 is expressed by CNS-infiltrating $\mathrm{F} 4 / 80^{+}$cells}

To further characterize the immune response to ROCV infection, we evaluated the expression levels of IL-33 and the levels of mRNA from ST2L (transmembrane form) receptor on CNS cells isolated from ROCVinfected animals. As observed in Fig. 3a, wild-type (WT) $\mathrm{BALB} / \mathrm{c}$ infected with a lethal dose of ROCV $\left(1.10^{6}\right.$ $\mathrm{PFU})$ had an increased infiltration of $\mathrm{F} 4 / 80^{+}$cells on CNS at 7 days post-infection. When we analyzed the levels of IL-33 expression by F4/80 ${ }^{+}$cells isolated from the CNS, we found increased IL-33 production following ROCV infection at day 7 (Fig. 3a). Moreover, a kinetic analysis of IL-33 and ST2L receptor mRNA levels on CNS-isolated cells from $1.10^{6}$ PFU ROCV-infected mice demonstrated a significant IL-33 response at day 5 postinfection and ST2L receptor upregulation at 5 and 7 days following infection (Fig. 3b, c). 

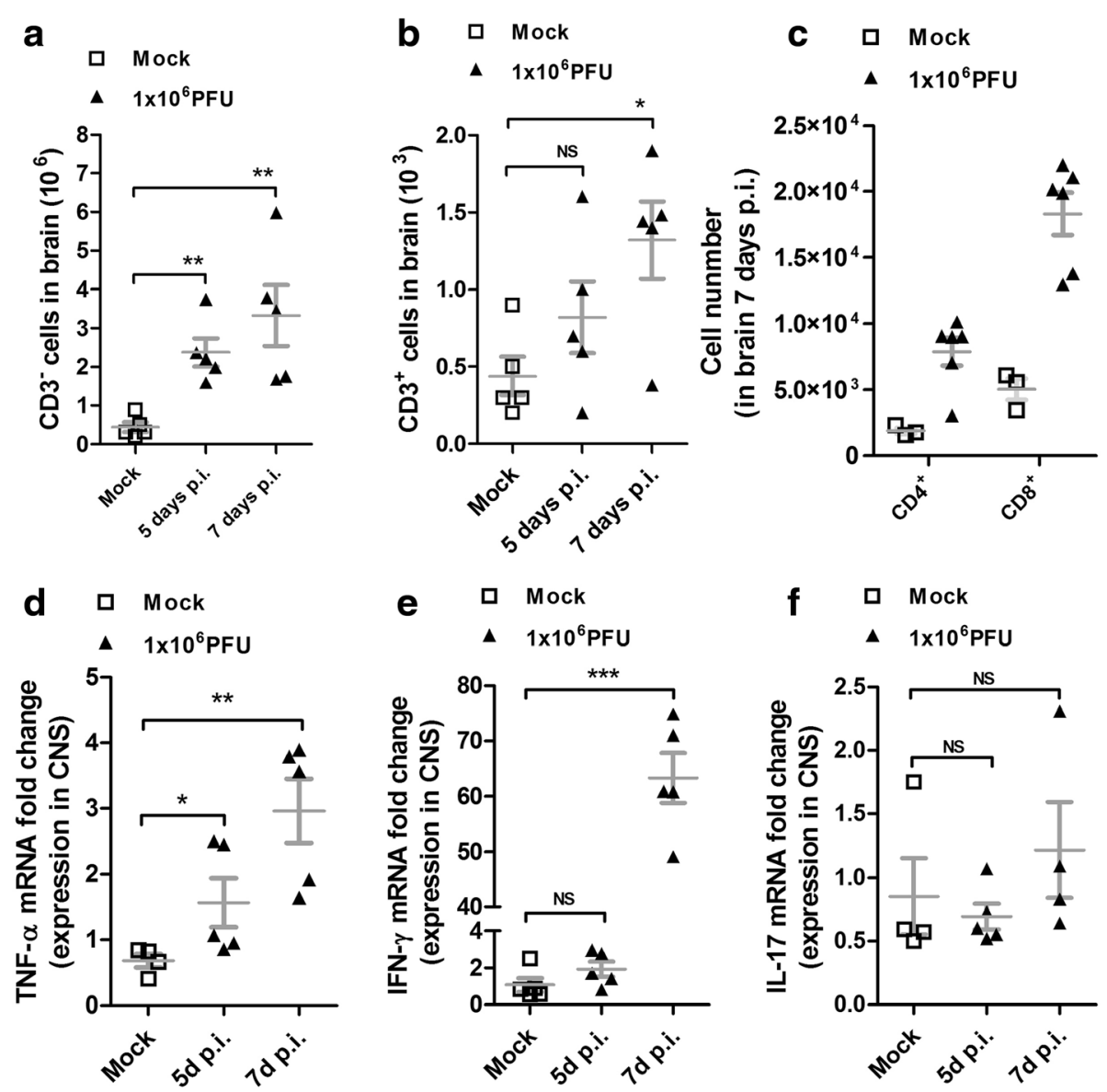

Fig. 2 Inflammatory profile in the brain of ROCV-infected BALB/C mice. a Number of CD3 ${ }^{-}$cells in the brain after 5 or 7 days of infection with ROCV $1.10^{6}$ PFU analyzed by FACS. $\mathbf{b}$ Number of $\mathrm{CD}^{+}$cells after ROCV infection as indicated. $\mathbf{c}$ Number of $\mathrm{CD} 4^{+}$- and $\mathrm{CD} 8^{+}$-infiltrating cells in the brain after 7 days post-infection (disease peak) with ROCV $1.10^{6} \mathrm{PFU}$, gated on $\mathrm{CD}^{+}$cells. $\mathbf{d}$ Expression levels of TNF-a mRNA in the brain of mice infected with ROCV $1.10^{6}$ PFU 5 and 7 days post-infection, analyzed by qPCR. e qPCR of IFN- $\gamma$ mRNA expression in the brains of ROCV-infected mice. $\mathbf{f} \mathrm{IL}-17 \mathrm{~A}$ mRNA expression. ${ }^{*} p<0.05,{ }^{* *} p<0.001$ or ${ }^{* * *} p<0.0001$. NS non-significant. Data are representative as the mean of three independent experiments with at least four animals per group. Statistical analysis was performed by Student $t$ test using the software GraphPad Prism
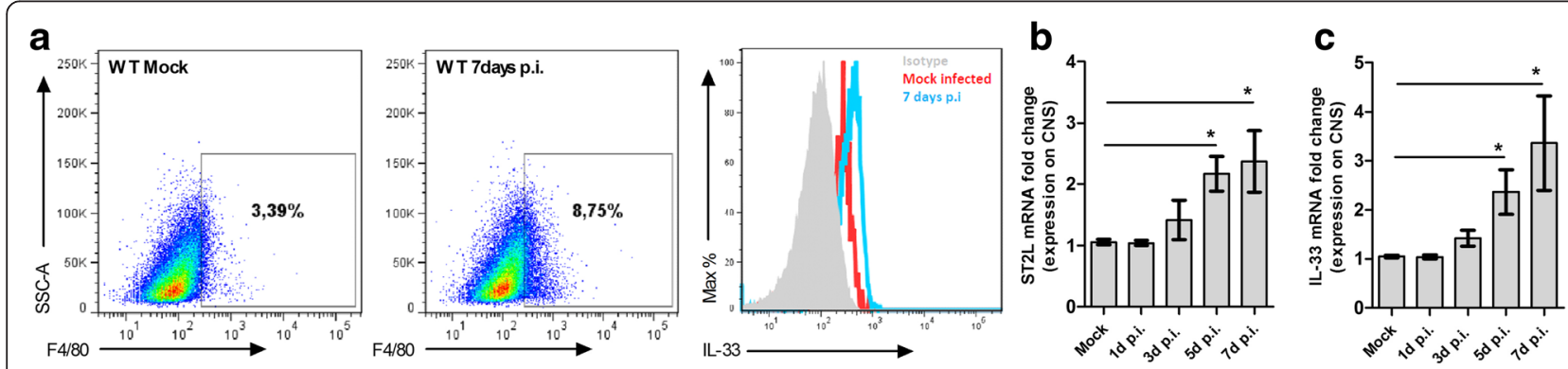

Fig. $3 \mathrm{IL}-33$ expression in CNS-infiltrating cells. a Frequency of F4/80 cells in the CNS of false infected WT mouse (WT mock), analyzed by FACS. Frequency of F $4 / 80^{+}$cells isolated from $1.10^{6}$ PFU ROCV-infected mouse 7 days after infection. (WT 7 days p.i.) Expression of IL-33 on F4/80 ${ }^{+}$gated cells isolated from CNS of mock and $1.10^{6} \mathrm{PFU}$ ROCV-infected mouse, analyzed by flow cytometry_FACS. Dots are representative from a single animal (with at least three animals per group). b, c Expression levels of IL-33 and ST2L (transmembrane form) mRNA in the brain of mice infected with ROCV $1.10^{6}$ PFU, analyzed by GPCR. Data are representative as the mean of three independent experiments with at least four animals per group. Statistical analysis was performed by unpaired Student $t$ test using the software GraphPad Prism 


\section{IL-33 deficiency contributes to viral encephalitis aggravation}

Among several biological activities of IL-33, the promotion of Th2 and inhibition of Th1 responses are well documented [14]. Here, given the strong upregulation of IL-1R4/ST2 observed on CNS from ROCV-infected mice, we aimed to investigate the role of IL-33/ST2 signaling on disease progression. Initially, we infected $\mathrm{WT}$ and $\mathrm{ST}^{-/-}$mice with different concentrations of $\mathrm{ROCV}$, and we observed no differences on survival when the animals were infected with either $1.10^{6}$ or $1.10^{5} \mathrm{PFU}$ (data not shown). However, when we infected mice by intraperitoneal route with a non-lethal dose of ROCV $\left(1.10^{4} \mathrm{PFU}\right)$ and compared the disease development on IL-33 receptor-deficient mouse $\left(\mathrm{ST}^{-/-}\right)$versus WT mice, we observed that wild-type mice are completely resistant to ROCV-induced encephalitis development; on the other hand, $\mathrm{ST} 2^{-/-}$mice experienced a $50 \%$ mortality rate up to 21 days post-infection as observed in Fig. 4a. Also, ST2 $2^{-/}$-infected mice presented a higher clinical score beginning as early as 8 days post-infection (Fig. 4b) and a higher viral load on CNS at 9 days postinfection (Fig. 4c) with apparent signs of encephalitis and evident cellular infiltrates at the CNS (Fig. 4g). Next, to elucidate the role of IL-33 on local cytokine modulation, we evaluated the mRNA expression of the Th2 key cytokine IL-4 (Fig. 4d) and pro-inflammatory cytokines IFN- $\gamma$ (Fig. 4e) and TNF- $\alpha$ (Fig. 4f) in the CNS and by enzyme-linked immunosorbent assay (ELISA) on the serum of infected animals (Fig. 4e, f). As observed, $\mathrm{ST} 2^{-/-}$mice had higher levels of TNF- $\alpha$ and IFN- $\gamma$ transcripts locally (at the CNS) when analyzed 9 days

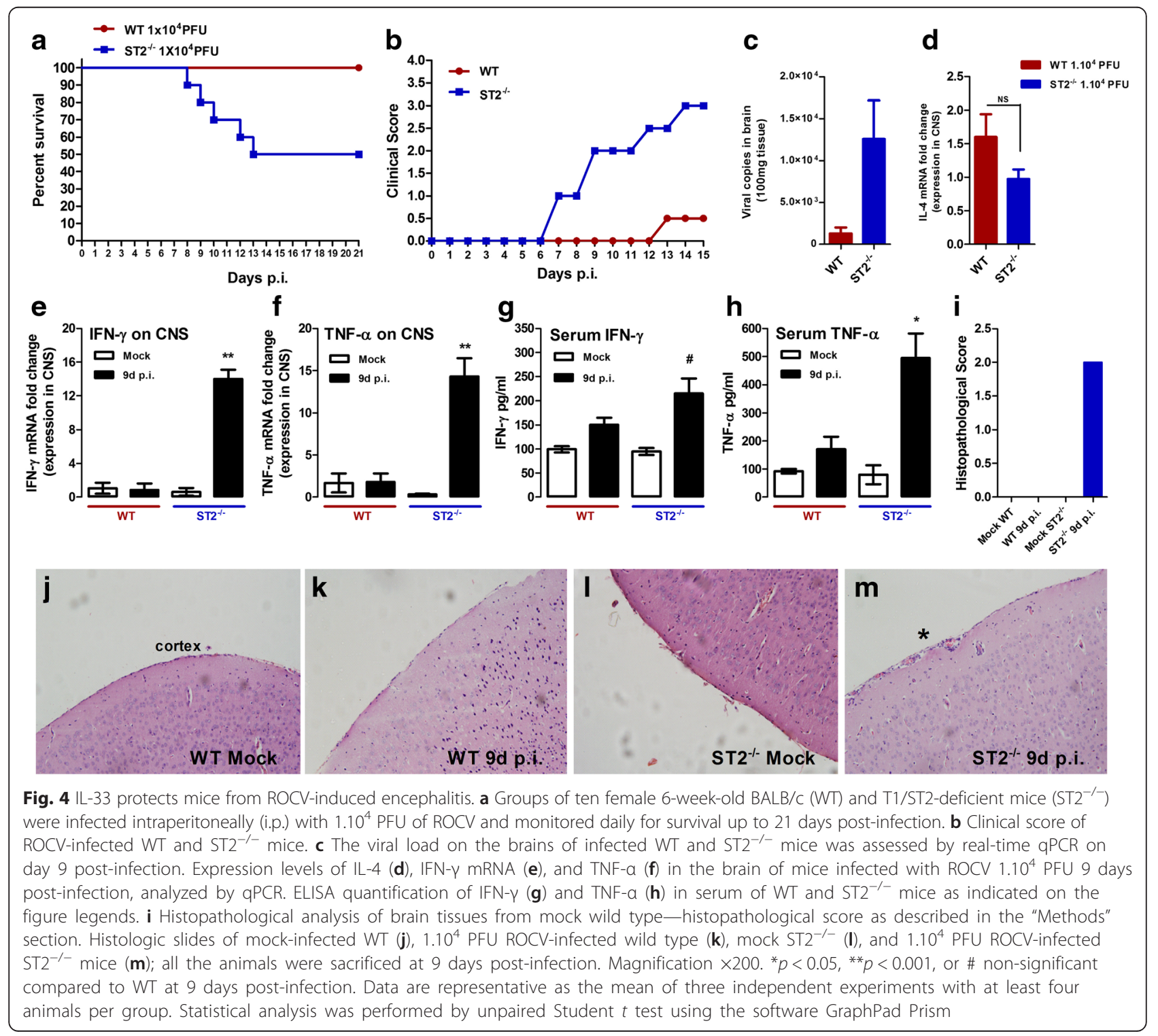


post-infection (when disease symptoms are evident on $\mathrm{ST} 2^{-/-}$mice); systemically (serum cytokines), the production of these cytokines were also increased, when compared to WT mice (Fig. 4g, h).

Histopathological analysis of CNS from mock and infected animals demonstrated a higher cellular infiltrate only on $\mathrm{ST}_{2}{ }^{-/}$animals following 9 days post-infection (Fig. 4i). Inflammatory cell infiltrates were not observed in CNS tissues from uninfected animals and the WT mouse (Fig. 4j-m). The histopathological scores were higher on the ST2 ${ }^{-/-}$-infected mouse (Fig. 4h). Mononuclear cellular infiltrates were concentrated mainly on meninges and cortex areas of $\mathrm{ST}_{2}^{-/-}$mice and were more prominent around blood vessels.

\section{Infiltrating lymphocytes contributes to disease progression by cytokine production}

To better understand the pathogenic mechanism of IL33 signaling on ROCV-induced encephalitis, we explored the cellular composition of CNS tissue and the cytokines being produced on WT versus $\mathrm{ST}^{-/-}$mice. FACS analysis of the CNS tissue 9 days post-infection demonstrated a cellular infiltrate constituted mainly by $\mathrm{CD} 4^{+}$ and $\mathrm{CD}^{+}{ }^{\mathrm{T}}$ cells (Fig. 5a, e). ST2 ${ }^{-/-}$-infected mice had an increased frequency of both $\mathrm{CD} 4^{+}$and $\mathrm{CD} 8^{+} \mathrm{T}$ cells; moreover, only $\mathrm{CD}^{+} \mathrm{CD}^{+}$cells produce significantly higher levels of IFN- $\gamma$ (Fig. 5c, g) but not TNF- $\alpha$ (Fig. 5d, h) or IL-10 (Fig. 5d, h) after the infiltrate of the CNS tissue.

\section{$\mathrm{ST}^{-1-}$ mice show increased iNOS expression in the CNS following ROCV infection}

In this study, we have found a higher proportion of lymphocytes infiltrating the CNS of ROCV-infected $\mathrm{ST}^{-1-}$ mice at 9 days post-infection, when the disease is evident; additionally, these cells appear to contribute to encephalitis aggravation by producing higher levels of pro-inflammatory cytokines. Thus, we hypothesized that the higher amounts of IFN- $\gamma$ released on $\mathrm{ST}^{-1-} \mathrm{CNS}$ mice could contribute to disease aggravation by shifting the local immune response to a Th1 profile, inducing a debalanced Th1/Th2 immune response and tissue damage. On type 2 innate lymphoid cells (ILC2), IL-33 signaling induces the production of Th2 cytokines such as IL-4, IL-5, and IL-13, leading to M2 macrophage polarization [15]. To check if the absence of IL-33 signaling could be affecting macrophage polarization, we evaluated the expression of the enzyme inducible nitric oxide synthase (iNOS), which metabolizes arginine to nitric oxide (NO) and is highly upregulated on M1 macrophages. Also, given that Stat 6 phosphorylation is mediated by IL-4 and that IL-4-mediated inhibition of iNOS expression on macrophages is Stat6 dependent [16], we investigated the potential role of Stat6 in ROCV-induced encephalitis. We analyzed by quantitative polymerase chain reaction (qPCR) the levels of iNOS (M1 macrophage marker) and arginase-1 (M2 macrophages marker) on CNS tissue from infected animals; on both groups $\left(\mathrm{ST}_{2}{ }^{-1-}\right.$ - and $\mathrm{Stat}^{-1-}$-infected mice), the mRNA levels

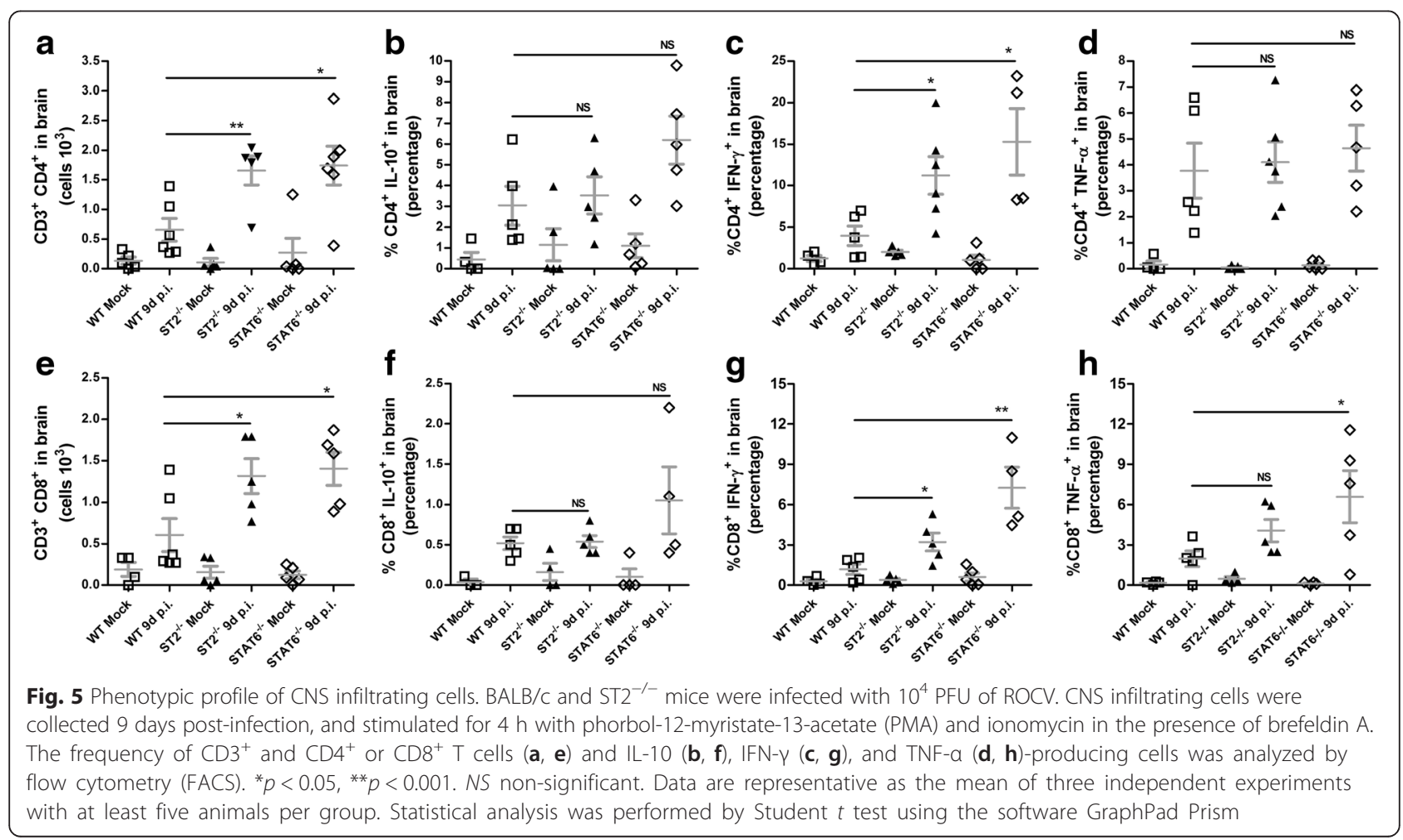


for iNOS (Fig. 6a), but not arginase-1 (Fig. 6b), were significantly upregulated at 9 days post-infection, compared to WT infected mice. To check which cells could be contributing to iNOS expression, we performed a FACS analysis of CNS cellular infiltrates. We observed a higher frequency of $\mathrm{CD} 45^{+} \mathrm{F} 4 / 80^{+}$ cells on $\mathrm{ST}^{-/-}$- and Stat6 ${ }^{-1-}$-infected mice $\left(1.10^{4}\right.$ $\mathrm{PFU})$ at 9 days post-infection, when compared to WT mice (Fig. 6c). Moreover, these cells were also expressing much higher levels of iNOS (Fig. 6d, e), analyzed by FACS on CNS-isolated $\mathrm{CD} 45^{+} \mathrm{F} 4 / 80^{+}$ gated cells. To complement our data, we checked survival and clinical score of Stat $6^{-/-}$mice and we observed similar results to $\mathrm{ST} 2^{-/-}$-infected mice, as well CNS-infiltrating lymphocyte profile and serum cytokines (Additional file 1: Figures S1 to S4).

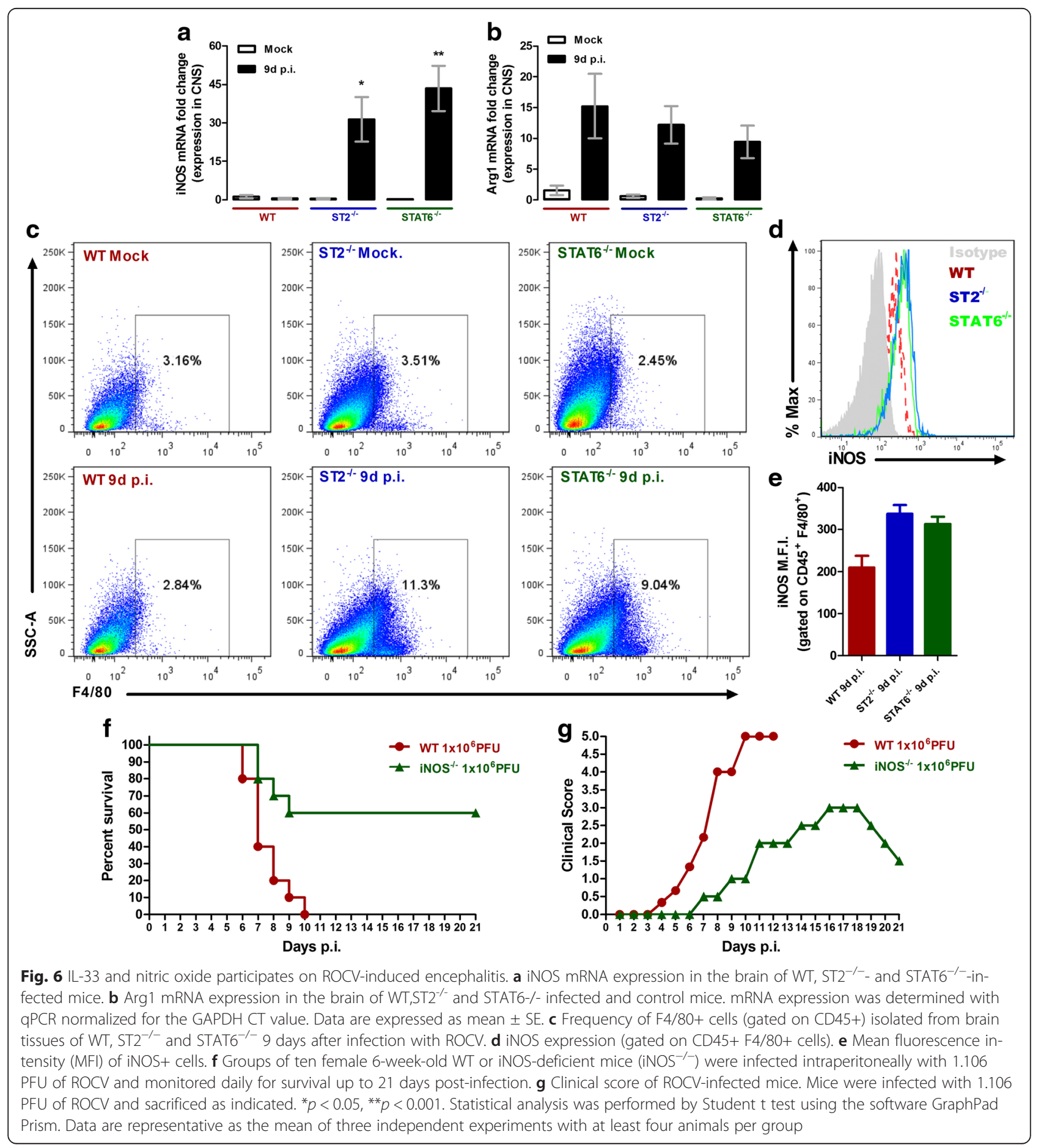




\section{iNOS deficiency protects mice from lethal viral encephalitis}

Finally, to check the role of $\mathrm{NO}$ on ROCV-induced experimental encephalitis, we infected $\mathrm{iNOS}^{-/-}$and WT C57BL/6 mice with a lethal dose of ROCV ( $\left.1.10^{6} \mathrm{PFU}\right)$ and monitored survival, clinical score, and tissue pathology on these animals. As observed in Fig. 6f, iNOS ${ }^{-1-}$ mice presented an increased survival rate than wild-type infected animals. Moreover, $\mathrm{iNOS}^{-1-}$ mice were partially protected from disease as evidenced by the lower clinical score (Fig. 6g). Interestingly, $\mathrm{iNOS}^{-/-}$mice CNS exhibited abundant cell infiltrates to levels compared to WT mice (Additional file 1: Figure S5) despite the increased survival rate.

\section{Discussion}

Understanding the pathogenic mechanisms of viral infections in the CNS is critical to encephalitis treatment. Previous reports demonstrate that CNS IL-33 signaling is related to protection following experimental infection with Toxoplasma gondii, and the authors found that IL33 deficiency leads to increased parasite burden and pathology in the brains of infected mice [17]. Here, in this study, we demonstrate that IL-33 has a protective role on experimental viral encephalitis. Our data supports previous studies in the literature demonstrating the contribution of IL-33 on T cell response modulation $[7,18]$. Here, the absence of ST2 (the receptor for IL-33) following the infection with an encephalitogenic virus leads to increased cellular-mediated immunopathology on mouse CNS.

Although the influenza A virus induced the production of IL-33 in alveolar macrophages and the activation of IL-13-producing natural helper cells and that after infection with coxsackievirus $\mathrm{B}, \mathrm{IL}-33$ in the pancreas is markedly elevated, data about the role of IL-33 signaling on viral infections are still scarce [8, 19]. Even though the participation of IL-33 is well documented on several different pathologies and disease conditions, we are the first to demonstrate the protective role of IL-33 signaling on viral experimental encephalitis. We are showing that IL-33 is expressed on the CNS following infection with a neurotropic virus, balancing the local immune response with consequent protection from exacerbated CNS injury. In fact, among other CNS pathologies, Jiang et al. [20] demonstrated that IL-33 administered after experimental autoimmune encephalomyelitis (EAE) onset could be protective against the disease and also that $\mathrm{ST}^{-/-}$mice developed exacerbated disease following EAE induction. Interestingly, recombinant IL-33 treatment attenuates EAE by suppression of IL-17 and interferongamma (IFN- $\gamma$ )-producing cells [20]. In addition, it was recently demonstrated that IL-33 is widely expressed on the healthy brain, especially by oligodendrocytes and gray matter astrocytes. Following CNS injury, induced by mechanical spinal cord contusion, IL-33 is immediately released acting on astrocytes and microglia to signal the production of chemokines that recruit monocytes and enhance M2 genes at the injury site involved in immunosuppression and tissue repair [21]. Thus, it seems that IL-33 production in response to CNS injury could represent a protective mechanism. In our model, the protective role of IL-33 is directly related to the local $\mathrm{T}$ cell response modulation, since IL-33 deficiency leads to augmented Th1 local immune response, with IFN- $\gamma$ overproduction and increased death following infection with ROCV. In fact, on viral infections, IFN- $\gamma$ is important to virus clearance; however, exacerbated IFN- $\gamma$ response could lead to tissue damage due to the extensive inflammation process, as observed in our results.

Given that IL-33 is characterized as a nuclear alarmin released after the cell is damaged, it is not surprising that a neurotropic virus such as ROCV could upregulate IL-33 production. ROCV infection induces degeneration and neuronal death, and apoptotic cells expressing caspase 3 (mainly neurons, lymphomononuclear and endothelial cells) were significantly increased across different CNS regions in later time points after ROCV infection. Viral antigens are usually detected on CNS after 4 days of infection [2]. In our results, we detected IL-33 expression also in later time points, coinciding with the detection of virus replication in the CNS. However, virus replication itself may not be the only factor inducing cell damage in the CNS; we suggest that the extensive injury might actually be a consequence of the inflammation, characterized by waives of cellular infiltration and local cytokine production. In this scenario, IL-33 is important to drive the expression of Th2-type cytokines which in turn can protect the animals by downregulating the CNS Th2-type inflammatory response. On the other hand, Th2 cytokines might not have a direct role on viral clearance. In fact, on viral infections of the CNS, the immune responses implicated on viral clearance are usually cell specific, for example, antibody responses are important to neurons and the $\mathrm{T}$ cell-mediated immune responses are more important to virus clearance from glial cells [22]. Upon ROCV infection, a mixed Th1/Th2 immune response is already documented [2]. Thus, it is crucial to identify specific immune factors that participate in protective virus response. In our analyses, we demonstrate a critical protective role of IL-33 signaling on CNS immune responses. However, the precise mechanisms of IL-33 synthesis, localization, and release during CNS viral inflammation remain to be fully characterized. Although we indentify macrophages expressing higher levels of IL-33 after infection, we cannot exclude that other CNS resident cells such as glial cells and astrocytes could be the main source of IL-33 production. In fact, it is previously demonstrated that 
astrocytes secrete IL-33 after inflammatory stimulation with TNF- $\alpha$ in vitro and that damaged neurons actively secrete IL-33 following EAE [23]. Moreover, it was recently demonstrated that dendritic cells can produce IL-33 after engagement of TLR4 and TLR5 receptors, and this leads to NF-kB activation and IL-33 expression following microbial stimulus [24]. The authors testify that the dendritic cell IL-33 could amplify local inflammatory response through an autocrine mechanism. More recently, Kim et al. [25] demonstrated that $\mathrm{CD} 11 \mathrm{c}^{\text {hi }}$ dendritic cells act on CNS by controlling the activation and function of infiltrated monocytes. By selective deletion of $\mathrm{CD} 11 \mathrm{c}^{\mathrm{hi}}$ dendritic cells, the authors found increased viral copies on CNS and death following mice infection with Japanese encephalitis virus; further analysis leads to the conclusion that CD11c ${ }^{\text {hi }}$-DC cells can regulate the activation of $\mathrm{CD} 11 \mathrm{~b}^{+} \mathrm{Ly}-6 \mathrm{C}^{\text {hi }}$ monocytes controlling exacerbated CNS inflammation [25]. In our study, the participation of dendritic cells was not addressed and further experiments are necessary to investigate the role of these cells on viral encephalitis.

Several different neurotropic viruses such as rabies virus (RABV), Japanese encephalitis virus (JEV), and West Nile virus (WNV) and more recently Zika virus present the potential to disrupt the blood brain barrier (BBB) and establish tissue damage [26-28]. The pathogenic mechanisms that contribute to BBB disruption are diverse, and chemokines or inflammatory cytokines such as IFN- $\gamma$, IL-8, TNF- $\alpha$, and IL- $1 \beta$ can indirectly contribute [29]. In this context, IFN- $\gamma$ has an important role. Following infection with JEV on the mouse, neutralization of IFN- $\gamma$ ameliorated the enhancement of BBB permeability. However, the administration of IFN- $\gamma$-neutralizing antibody did not significantly change the viral load on CNS [27]. Thus, it seems that IFN- $\gamma$ production on CNS could act by breaking the BBB allowing or facilitating the infiltration and activation of resident cells such as microglia. Interestingly, microglia activation has been suggested to be responsible for the progression of neuronal damage-releasing neurotoxic factors such as TNF- $\alpha$ or nitric oxide (NO) [30]. In conclusion, given that all these pro-inflammatory factors are cytotoxic to neurons, IL-33 signaling on CNS is crucial to balance the local inflammatory process by avoiding excessive proinflammatory cytokine production, protecting the neurons from extensive damage. In our model, we observed higher levels of both mediators: IFN- $\gamma$ and NO, following infection of IL-33 signaling-deficient mouse $\left(\mathrm{ST}^{-{ }^{--}}\right)$with ROCV. Thus, microglia overactivation through NO production could serve to enhance or amplify the neuronal damage induced by virus replication. Additionally, we observed a higher viral load on the $\mathrm{CNS}$ of $\mathrm{ST}_{2}^{-/-}$mice; this could be partly explained by the fact that the IL-33-deficient mouse presented higher frequencies of cellular infiltrates in the brain (providing more cells that can be infected). On the other hand, IL-33 signaling is necessary to generate effective $\mathrm{CD} 8^{+} \mathrm{T}$ cell responses in viral and tumor metastatic models $[12,31]$. Thus, ineffective cytotoxic T cell lymphocyte (CTL) response (CTL) by the lack of IL-33 could favor ROCV replication in our model, although a more detailed study on CTL function could provide more solid data.

Numerous pathological conditions such as Alzheimer's disease, Parkinson's disease, and multiple sclerosis are well known to induce neurodegeneration [32]. The mechanisms of neuroinflammation are dependent on glial cell activation, which releases a number of neurotoxic factors, especially nitric oxide species (NOS) and cytokines. In the $\mathrm{CNS}$, the production of pro-inflammatory molecules results in apoptosis in various subsets of resident brain cells. Interestingly, NO has a neuroprotective effect at physiological levels; however, NO becomes harmful if it is produced in excess, leading to neuronal damage [33]. Usually, iNOS expression in the CNS is very low and can be induced in astrocytes or microglial cells following events such as viral infection. In fact, it has been reported that in vitro infection of mouse macrophages with ROCV leads to $\mathrm{NO}$ production [34]. Here, the induction of $\mathrm{NO}$ release by virus infection is highly amplified on the $\mathrm{ST} 2^{-/-}$mouse as a direct consequence of augmented Th1 response on the CNS. This was associated with the increased CNS infiltration of immune cells, particularly Th1 cells. Higher levels of IFN- $\gamma$ can act by shifting infiltrating macrophages to the M1 phenotype, as evidenced by a higher expression of iNOS transcripts on infected mouse CNS. M1 macrophages are cytotoxic and exhibit pro-inflammatory markers, characterized by the production of pro-inflammatory cytokines and high levels of reactive oxygen and nitrogen species [35]. Importantly, it was recently reported that the lack of IL-33 signaling in CNS results in lower levels of infiltrating neuroprotective M2 macrophages, which, in turn, leads to impaired recovery after CNS mechanical injury [21]. Thus, here we provide evidence that following viral infection, IL-33 is produced in the CNS to counteract the deleterious effects of pro-inflammatory cytokines IFN- $\gamma$ and TNF- $\alpha$, as well to shift macrophage response to a M2-protective phenotype.

We previously demonstrated that ROCV infection results in increasing diffuse neuronal degeneration starting at 4 days post-infection, with positive caspase 3 glial and neuronal cells at 9 days post-infection [2]. Nitric oxide production in the CNS is highly toxic to neurons. Thus, we hypothesized that NO release in the CNS could represent the most downstream event on IL-33 local response modulation. Another function of $\mathrm{NO}$ is to act as a negative regulator of immune cell trafficking to the CNS [36]. It is very interesting that the macrophage 
from the M1 phenotype infiltrates injured CNS tissue via CCL2 signaling through adjacent spinal cord leptomeninges; on the other hand, M2 cells came from monocytes that trafficked through the brain-ventricular choroid plexus (CP), via the VCAM-1-VLA4 and CD73 mechanism [37]. At the CP, NO inhibits NF-kB/p65 translocation to the nucleus and sequential leukocyte entry to the CNS [36]. In our results, we observed higher cellular infiltrates in $\mathrm{iNOS}^{-/}$-infected mice (Additional file 1: Figure S5); however, iNOS deficiency results in increased survival rates following ROCV infection despite the higher pathological scores. Thus, taken together, our data support the idea that NO production in the CNS is the most neurotoxic product.

\section{Conclusions}

Taken together, our data indicate a direct role of IL-33 signaling on CNS immunopathology control. The absence of IL-33 signaling increases the CNS inflammation by a mechanism dependent on IFN- $\gamma$ production that leads to NO production and consequent tissue damage. Finally, the data presented here may contribute to the design of new therapies to viral encephalitis based on the benefits of IL-33 administration or the blockade of its receptor ST2 to avoid extensive damage elicited by the immune response to CNS insults.

\section{Methods}

\section{Virus}

ROCV (SPH34675 strain) was used for mouse infection and kindly provided by Prof. Dr. Luiz Tadeu M. Figueiredo, Ribeirão Preto School of Medicine, University of São Paulo-Brazil. Virus stocks were obtained from the brains of intracerebrally infected suckling mice. Mouse brains were aspirated and macerated in phosphate-buffered saline (PBS) and centrifuged at $500 \mathrm{~g}$ for $10 \mathrm{~min}$ at $4{ }^{\circ} \mathrm{C}$, and supernatants were collected and stored at $-70{ }^{\circ} \mathrm{C}$ until use. Viral stocks were titrated by the plaque-forming unit (PFU) assay, as previously described [38].

\section{Animal experimentation}

Wild-type BALB/c (WT), ST2-deficient (T1/ST2 ${ }^{-/}$), and Stat6-deficient $\left(\mathrm{Stat6}^{-/-}\right.$) mice were infected by intraperitoneal route with different concentrations of ROCV stocks, as stated. C57/B6 wild type and iNOS ${ }^{-/-}$ were infected by intraperitoneal route of ROCV. A mock control group (false infected) was inoculated with extracts from uninfected brain in PBS/albumin $7.5 \%$ by the same route, and volume as used for the virus infection The clinical score was monitored daily, and the animals were scored accordingly to the following: 0 normal mouse, no overt signs of disease; 1 limp tail or hind limb weakness; 2 limp tail and hind limb weakness; 3 partial hind limb paralysis; 4 complete hind limb paralysis; and
5 moribund state, death by encephalitis (sacrifice for ethical reasons). Survival was monitored daily up to 21 days. For tissue collection, the animals were sacrificed on different days post-infection (p.i.) as indicated and perfused and tissues samples were collected for analysis. A blood sample was collected to quantify the levels of serum cytokines by ELISA. The animals were housed at five per cage with food and water available ad libitum. All experiments were conducted in accordance with the prescribed guidelines on experimental animal welfare of the National Institutes of Health and were approved by the Ethics Committee of the Ribeirão Preto Medical School, University of São Paulo.

\section{Histopathological analysis and CNS histologic scores}

Histologic scores were performed in the CNS of infected and control mice at 9 days post-infection. Briefly, animals were euthanized and perfused, and brain tissue was removed and fixed in $10 \%$ formaldehyde. Tissues were dehydrated in graded ethanol and embedded in a $100 \%$ paraffin block. Serial sections with $5-\mu$ m thickness were prepared and stained with hematoxylin and eosin. Five to six photos were obtained for each animal. The extent of meningeal inflammation was assessed and graded as follows: 0, no inflammation (total absence of inflammatory cells at the meninges area); 1 , one cell layer of inflammation (a single layer of infiltrating cells at the meninges); 2, two cell layers of inflammation (two cell layers at the meninges area); 3 , three cell layers of inflammation; 4, four cell layers; and 5, five or more cell layers of inflammation. The area with the maximal extent of tissue damage was used for the assessment of each brain region.

\section{Clinical scores}

The clinical score was assessed daily as described by Miller et al. [39]. Briefly, the following grades were considered: 0 normal mouse, no signs of disease; 1 limp tail or hind limb weakness (but not both); 2 limp tail and hind limb weakness (both symptoms manifestation); 3 partial hind limb paralysis; 4 complete hind limb paralysis; and 5 moribund state (euthanasia performed for ethical issues).

\section{Tissue quantification of cytokine mRNAs and viral load}

Total RNA from brain samples (approximately $100 \mathrm{mg}$ from each animal time point) was extracted with the TRIzol Reagent (Life Technologies, Carlsbad, CA, USA) according to the manufacturer's instructions. After extraction, RNA was quantified by absorbance at $260 \mathrm{~nm}$ and approximately $1 \mu \mathrm{g}$ of each sample was used to obtain the complementary DNA (cDNA) strands using the SuperScript III enzyme (Life Technologies) and Oligo(dT)12-18 for first strand synthesis, according to 
the manufacturer's instruction. Real-time polymerase chain reaction (PCR) analysis of cytokine mRNA profiles was performed with the Power SYBR ${ }^{\circ}$ Green Master Mix kit (Applied Biosystems, CA, USA), and reactions were processed in ABI7500 equipment (Applied Biosystems). The results were analyzed on the basis of the cycle threshold $(\mathrm{Ct})$ of target genes, and the level of expression was calculated by comparing to an endogenous control gene ( $\beta$-actin) using the $\Delta \Delta \mathrm{Ct}$ method (relative amount of target gene for each sample is quantified by the equation $\left.2^{-\Delta \Delta C t}\right)$; data were analyzed with the comparative $\mathrm{Ct}$ method. The reactions were carried out in a final volume of $25 \mu \mathrm{l}$ containing $12.5 \mu \mathrm{l}$ of SYBR Green PCR Master Mix, $0.5 \mu \mathrm{M}$ of each primer (designed on the basis of the mRNA sequence of the cytokine genes), and $5 \mu \mathrm{l}$ of cDNA. RT-PCR cycles were $95{ }^{\circ} \mathrm{C}$ for $15 \mathrm{~s}$ and $60{ }^{\circ} \mathrm{C}$ for $1 \mathrm{~min}$, and the dissociation curve was constructed by increasing temperatures from 60 to $90{ }^{\circ} \mathrm{C}$. Viral copies were determined by $\mathrm{qPCR}$, as described above. A standard curve from a previous established virus stock was serially diluted to construct a standard curve, and viral copies were determined from each sample analyzed; results were expressed as viral copies in the brain per $100 \mathrm{mg} /$ tissue. Primers used for cytokine quantification are listed in Table 1.

\section{Viral titration}

Viral stocks were titrated by the PFU assay. Briefly, Vero cells were cultivated in 24-well plates, and cell-confluent monolayers were infected with $100 \mu \mathrm{l}$ of serial dilutions of the viral stocks. Next, the cells were incubated for $1.5 \mathrm{~h}$ at $37^{\circ} \mathrm{C}$ and washed with PBS, and an overlay consisting of DMEM containing $2 \%$ fetal bovine serum and $3 \%$ carboxymethylcellulose was added to the wells. The cells were then incubated for 7 days at $37{ }^{\circ} \mathrm{C} / 5 \% \mathrm{CO}_{2}$. After this period of incubation, the overlay was discarded and the cells were washed with PBS and stained with $0.5 \%$ Neutral Red solution. The viral titer was based on the number of plaques present in the highest dilution.

\section{Cytokine quantification ELISA}

Serum samples were used to quantify the levels of IFN- $\gamma$ and TNF- $\alpha$ using commercial kits (R\&D Systems, Abingdon, UK). ELISA was performed by coating 96-well polystyrene microtiter plates with the specific antibody. After blocking, standards and samples were and the plates were incubated overnight at $4{ }^{\circ} \mathrm{C}$. A specific biotinylated antibody was added to all wells and incubated for $1 \mathrm{~h}$ at room temperature. The plates were washed and incubated for $30 \mathrm{~min}$ with horseradish peroxidase-conjugated streptavidin. 3-3',5,5'tetramethylbenzidine (TMB) substrate reagent solution
Table 1 Primers used for gene expression analysis

\begin{tabular}{|c|c|}
\hline Targets & Primer sequences $\left(5^{\prime} \geq 3^{\prime}\right)$ \\
\hline \multirow[t]{2}{*}{ IFN- $\gamma$} & F: ATCAGGAGGGACTCCTITTCCGCTT \\
\hline & R: GAAGCCTAGAAAGTCTGAATAACT \\
\hline \multirow[t]{2}{*}{ IL-17A } & F: GGTCAACCTCAAGTCIITAACTC \\
\hline & R: TTAAAAATGCAAGTAAGTTTGCTG \\
\hline \multirow[t]{2}{*}{ TNF-a } & F: ACCAGCTAAGAGGGAGAGAAGCAA \\
\hline & R: TCAGTGCTCATGGTGTCCTITCCA \\
\hline \multirow[t]{2}{*}{ IL-33 } & F: TCCTTGCTTGGCAGTATCCA \\
\hline & R: TGCTCAATGTGTCAACAGACG \\
\hline \multirow[t]{2}{*}{ ST2L } & F: CATGGCATGATAAGGCACAC \\
\hline & R: GTAGAGCTTGCCATCGTTCC \\
\hline \multirow[t]{2}{*}{ iNOS } & F: CAGTTCCGAGCGTCAAAGACCTGC \\
\hline & R: CAGCCCAACAATACAATACAAGATG \\
\hline \multirow[t]{2}{*}{$\arg 1$} & F: GTTCCCAGATGTACCAGGATTC \\
\hline & R: CGATGTCTITGGCAGATATGC \\
\hline \multirow[t]{2}{*}{ IL-4 } & F: GAATGTACCAGGAGCCATATC \\
\hline & R: CTCAGTACTACGAGTAATCCA \\
\hline \multirow[t]{2}{*}{$\beta$-actin } & F: AGCTGCGTTITACACCCTIT \\
\hline & R: AAGCCATGCCAATGTTGTCT \\
\hline \multirow[t]{2}{*}{ ROCV—SPH34675-NS5 } & F: GGTCAATGCCACAAGCCAAG \\
\hline & R: CTTCAGCCTTTCGATCCGGT \\
\hline
\end{tabular}

(Sigma-Aldrich) was added to the wells. Absorbance was read at $450 \mathrm{~nm}$.

\section{Flow cytometry}

Mice were perfused with PBS before the brains were harvested. Brain tissues were pretreated with $2 \mu \mathrm{g} / \mathrm{ml}$ collagenase D and $1 \mu \mathrm{g} / \mathrm{ml}$ DNAse I (both Roche Diagnostics), and total cells were isolated by cell straining $(100-\mu \mathrm{m}$ mesh). Brain homogenates were separated into neuronal and leukocyte populations by discontinuous density gradient centrifugation using isotonic Percoll (GE HealthCare, Uppsala, Sweden) as described by Pino and Cardona [40]. After isolation, cells were stimulated in vitro with PMA and Ionomycin plus BD GolgiStop ${ }^{\mathrm{Tm}}$ (BD Biosciences, San Jose, CA, USA) for at least $4 \mathrm{~h}$ at $37^{\circ} \mathrm{C}$. After stimulation, the cells were fixed with BD Cytofix/Cytoperm ${ }^{\text {тा }}$ Plus Fixation/Permeabilization Kit and intracellular staining was carried out following the manufacturer's instructions (BD Biosciences). Flow cytometry was performed using a FACS Verse (BD Biosciences) with the specific antibodies listed: anti-CD45 clone A20, anti-CD4 clone GK1.5, CD8 $\alpha$ clone 5H10-1, IFN- $\gamma$ clone XMG1.2, TNF- $\alpha$ clone MP6XT22, CD3 clone 17A2, IL-10 clone JES5-16E3, F4/80 clone BM8 (all from BioLegend Inc., San Diego, CA, USA), IL-33 clone 396118 (R\&D Systems, Minneapolis, MN, USA), and anti-iNOS (NOS2) clone N-20 (Santa Cruz Biotechnology, San Diego, CA, USA). 


\section{Statistical analysis}

The data are reported as the means \pm SEM. Student's $t$ test was used to test for statistical significance of the differences between the different group parameters. $p$ values of less than 0.05 were considered statistically significant. When necessary, statistical analysis was performed by either one-way ANOVA or two-way ANOVA with Bonferroni post-test as stated on figure legends.

\section{Additional file}

Additional file 1: Figure S1. Phenotypic profile of CNS-infiltrating cells on $\mathrm{Stat}^{-/-}$mice. Figure $\mathbf{S} \mathbf{2}$. Stat $6^{-/-}$mice survival after ROCV infection. Figure S3. Cytokine profile on Stat6 ${ }^{-/-}$mice. Figure S4. Effect of ROCV infection on transaminases and urea profile on $\mathrm{WT}, \mathrm{ST}^{-1-}$, and Stat $6^{-1}$ mice. Figure S5. Nitric oxide deficiency leads to increased histopathological score on CNS ROCV-induced encephalitis. Figure S6. Gating strategy for macrophage F4/80+ cell analysis.

\section{Abbreviations}

BBB, blood brain barrier; CCL2, chemokine (C-C motif) ligand 2; CCR5 C-C, chemokine receptor type 5; CD11b, cluster of differentiation 11b; CD11c, cluster of differentiation 11c; CD3, cluster of differentiation 3; CD4+, cluster of differentiation 4; CD45+ cluster of differentiation $45 ; C D 73$, cluster of differentiation 73; CD8+, cluster of differentiation 8; CDNA, complementary DNA; CNS, central nervous system; $C P$, choroid plexus; CTL, cytotoxic T lymphocyte; DMEM, Dulbecco's minimal essential media; EAE, experimental autoimmune encephalomyelitis; ELISA, enzyme-linked immunosorbent assay: FACS, fluorescent-activated cell sorting; IFN- $\gamma$, interferon-gamma; IL-10, interleukin 10; IL-13, interleukin 13; IL-17A, interleukin 17A; IL-1 3 , interleukin 1 beta; IL-33, interleukin 33; IL-4, interleukin 4; IL-5, interleukin 5; IL-8, interleukin 8 ; iNOS, inducible nitric oxide synthase; JEV, Japanese encephalitis virus; Ly-6C, lymphocyte antigen 6 complex; MIP-1a, macrophage inflammatory protein 1 alpha; mRNA, messenger ribonucleic acid; MyD88, myeloid differentiation primary response gene 88; NF-kB, nuclear factor kappa b; NO, nitric oxide; p.i., post-infection; PBS, phosphate-buffered saline; PCR, polymerase chain reaction; $\mathrm{PFU}$, plaque forming unit; $\mathrm{QPCR}$, quantitative polymerase chain reaction; RABV, rabies virus; RNA, ribonucleic acid; ROCV, Rocio virus; RT-PCR, reverse-transcription polymerase chain reaction; Th1, T helper 1; Th2, T helper 2; TNF-a, tumor necrosis factor alpha; VCAM-1, vascular cell adhesion protein 1; VLA-4, very late antigen 4; WNV, West Nile virus; $W T$, wild type

\section{Funding}

The research leading to these results received funding from the European Union Seventh Framework Programme (FP7-2007-2013) under grant agreement no. HEALTH-F4-2011-281608 (TIMER), the São Paulo Research Foundation (FAPESP) under grant agreements nos. 2011/19670-0 (Thematic Project), from the University of São Paulo NAP-DIN under grant agreement no. 11.1.21625.01.0. and 2013/08216-2 (Center for Research in Inflammatory Disease) under FQC coordination and responsibility. R.F.O.F received a postdoctoral fellowship from the São Paulo Research Foundation (FAPESP) under grant number 2010/19770-2.

\section{Availability of data and materials}

No data will be shared. The current manuscript does not currently use any software, database (including arrays), or method necessary to be freely available to public.

\section{Authors' contributions}

RFOF performed the mouse experimentation, cytometry, and qPCR and wrote the manuscript; RSC performed mouse experimentation and cytometry; JRS, RSP, LRM, DFC, and JCAF performed the data analysis support, cytometry, and discussions; FQC supervised the project, revised the manuscript, and financed the study. All authors read and approved the final manuscript.

\section{Competing interests}

The authors declare that they have no competing interests.
Consent for publication

Not applicable.

\section{Ethics approval and consent to participate}

All experiments were conducted in accordance with the prescribed guidelines on experimental animal welfare of the National Institutes of Health and were approved by the Ethics Committee of the Ribeirão Preto Medical School, University of São Paulo.

\section{Author details}

'Department of Virology and Experimental Therapy LAVITE, Oswaldo Cruz Foundation - FIOCRUZ, Institute Aggeu Magalhães IAM, Av. Professor Moraes Rego, s/n, Recife, PE 50740-465, Brazil. ${ }^{2}$ Program of Basic and Applied Immunology, University of São Paulo, Ribeirao Preto, SP 14049-900, Brazil. ${ }^{3}$ Department of Pharmacology, Ribeirão Preto School of Medicine, University of São Paulo, Ribeirão Preto, SP 14049-900, Brazil.

Received: 23 February 2016 Accepted: 15 June 2016

Published online: 22 June 2016

\section{References}

1. Tanaka H, Weigl DR, de Souza LO. The replication of Rocio virus in brain tissue of suckling mice. Study by electron microscopy. Arch Virol. 1983;78:309-14

2. de Barros VE, Saggioro FP, Neder L, de Oliveira Franca RF, Mariquela V, Chavez JH, Penharvel S, Forjaz J, da Fonseca BA, Figueiredo LT. An experimental model of meningoencephalomyelitis by Rocio flavivirus in BALB/c mice: inflammatory response, cytokine production, and histopathology. Am J Trop Med Hyg. 2011;85:363-73.

3. Chavez JH, Franca RF, Oliveira CJ, de Aquino MT, Farias KJ, Machado PR, de Oliveira TF, Yokosawa J, Soares EG, da Silva JS et al. Influence of the CCR-5/ MIP-1 alpha axis in the pathogenesis of Rocio virus encephalitis in a mouse model. Am J Trop Med Hyg. 2013;89:1013-8.

4. Schmitz J, Owyang A, Oldham E, Song Y, Murphy E, McClanahan TK, Zurawski G, Moshrefi M, Qin J, Li X et al. IL-33, an interleukin-1-like cytokine that signals via the IL-1 receptor-related protein ST2 and induces T helper type 2-associated cytokines. Immunity. 2005;23:479-90.

5. Liew FY, Pitman NI, McInnes IB. Disease-associated functions of IL-33: the new kid in the IL-1 family. Nat Rev Immunol. 2010;10:103-10.

6. Talabot-Ayer D, Calo N, Vigne S, Lamacchia C, Gabay C, Palmer G. The mouse interleukin (II)33 gene is expressed in a cell type- and stimulus-dependent manner from two alternative promoters. J Leukoc Biol. 2012:91:119-25.

7. Xu D, Chan WL, Leung BP, Huang F, Wheeler R, Piedrafita D, Robinson JH, Liew FY. Selective expression of a stable cell surface molecule on type 2 but not type 1 helper T cells. J Exp Med. 1998;187:787-94.

8. Sesti-Costa R, Silva GK, Proenca-Modena JL, Carlos D, Silva ML, Alves-Filho JC, Arruda E, Liew FY, Silva JS. The IL-33/ST2 pathway controls coxsackievirus B5-induced experimental pancreatitis. J Immunol. 2013;191:283-92.

9. Rostan O, Gangneux JP, Piquet-Pellorce C, Manuel C, McKenzie AN, Guiguen C, Samson M, Robert-Gangneux F. The IL-33/ST2 axis is associated with human visceral leishmaniasis and suppresses Th1 responses in the livers of BALB/C mice infected with Leishmania donovani. MBio. 2013;4:e00383-00313.

10. Hung LY, Lewkowich IP, Dawson LA, Downey J, Yang Y, Smith DE, Herbert DR. IL-33 drives biphasic IL-13 production for noncanonical type 2 immunity against hookworms. Proc Natl Acad Sci U S A. 2013;110:282-7.

11. Yasuda K, Muto T, Kawagoe T, Matsumoto M, Sasaki Y, Matsushita K, Taki Y, Futatsugi-Yumikura S, Tsutsui H, Ishii KJ et al. Contribution of IL-33-activated type II innate lymphoid cells to pulmonary eosinophilia in intestinal nematode-infected mice. Proc Natl Acad Sci U S A. 2012;109:3451-6.

12. Bonilla WV, Frohlich A, Senn K, Kallert S, Fernandez M, Johnson S, Kreutzfeldt M, Hegazy AN, Schrick C, Fallon PG et al. The alarmin interleukin-33 drives protective antiviral CD8(+) T cell responses. Science. 2012;335:984-9.

13. Jackson DJ, Makrinioti H, Rana BM, Shamji BW, Trujillo-Torralbo MB, Footitt J, Jerico D-R, Telcian AG,Nikonova A, Zhu J et al. IL-33-dependent type 2 inflammation during rhinovirus-induced asthma exacerbations in vivo. Am J Respir Crit Care Med. 2014;190:1373-82.

14. Villarreal DO, Weiner DB. Interleukin 33: a switch-hitting cytokine. Curr Opin Immunol. 2014;28:102-6. 
15. Kurowska-Stolarska M, Stolarski B, Kewin P, Murphy G, Corrigan CJ, Ying S, Pitman N, Mirchandani A, Rana B, van Rooijen N et al. IL-33 amplifies the polarization of alternatively activated macrophages that contribute to airway inflammation. J Immunol. 2009;183:6469-77.

16. Hiroi M, Sakaeda Y, Yamaguchi H, Ohmori Y. Anti-inflammatory cytokine interleukin-4 inhibits inducible nitric oxide synthase gene expression in the mouse macrophage cell line RAW264.7 through the repression of octamer-dependent transcription. Mediators Inflamm. 2013;2013:369693.

17. Jones LA, Roberts F, Nickdel MB, Brombacher F, McKenzie AN, Henriquez FL, Alexander J, Roberts CW et al. IL-33 receptor (T1/ST2) signalling is necessary to prevent the development of encephalitis in mice infected with Toxoplasma gondii. Eur J Immunol. 2010;40:426-36.

18. Lohning M, Stroehmann A, Coyle AJ, Grogan JL, Lin S, Gutierrez-Ramos JC, Levinson D, Radbruch A, Kamradt T. T1/ST2 is preferentially expressed on murine Th2 cells, independent of interleukin 4, interleukin 5, and interleukin 10, and important for Th2 effector function. Proc Natl Acad Sci U S A. 1998; 95:6930-5.

19. Chang YJ, Kim HY, Albacker LA, Baumgarth N, McKenzie AN, Smith DE Dekruyff RH, Umetsu DT. Innate lymphoid cells mediate influenza-induced airway hyper-reactivity independently of adaptive immunity. Nat Immunol. 2011;12:631-8.

20. Jiang HR, Milovanovic M, Allan D, Niedbala W, Besnard AG, Fukada SY, Alves-Filho JC, Togbe D, Goodyear CS, Linington C et al. IL-33 attenuates EAE by suppressing IL-17 and IFN-gamma production and inducing alternatively activated macrophages. Eur J Immunol. 2012;42:1804-14.

21. Gadani SP, Walsh JT, Smirnov I, Zheng J, Kipnis J. The glia-derived alarmin IL-33 orchestrates the immune response and promotes recovery following CNS injury. Neuron. 2015:85:703-9.

22. Griffin DE. Immune responses to RNA-virus infections of the CNS. Nat Rev Immunol. 2003;3:493-502.

23. Chen H, Sun Y, Lai L, Wu H, Xiao Y, Ming B, Gao M, Zou H, Xiong P, Xu Y et al. Interleukin-33 is released in spinal cord and suppresses experimental autoimmune encephalomyelitis in mice. Neuroscience. 2015;308:157-68.

24. Su Z, Lin J, Lu F, Zhang X, Zhang L, Gandhi NB, de Paiva CS, Pflugfelder SC, Li DQ. Potential autocrine regulation of interleukin-33/ST2 signaling of dendritic cells in allergic inflammation. Mucosal Immunol. 2013;6:921-30.

25. Kim JH, Choi JY, Kim SB, Uyangaa E, Patil AM, Han YW, Park SY, Lee JH, Kim K, Eo SK. CD11C(hi) dendritic cells regulate Ly-6C(hi) monocyte differentiation to preserve immune-privileged CNS in lethal neuroinflammation. Sci Rep. 2015;5:17548.

26. Roe K, Kumar M, Lum S, Orillo B, Nerurkar VR, Verma S. West Nile virusinduced disruption of the blood-brain barrier in mice is characterized by the degradation of the junctional complex proteins and increase in multiple matrix metalloproteinases. J Gen Virol. 2012;93:1193-203.

27. Li F, Wang Y, Yu L, Cao S, Wang K, Yuan J, Wang C, Cui M, Fu ZF. Viral infection of the central nervous system and neuroinflammation precede blood-brain barrier disruption during Japanese encephalitis virus infection. J Virol. 2015:89:5602-14.

28. Kuang Y, Lackay SN, Zhao L, Fu ZF. Role of chemokines in the enhancement of BBB permeability and inflammatory infiltration after rabies virus infection. Virus Res. 2009;144:18-26.

29. Toborek M, Lee YW, Flora G, Pu H, Andras IE, Wylegala E, Hennig B, Nath A. Mechanisms of the blood-brain barrier disruption in HIV-1 infection. Cell Mol Neurobiol. 2005;25:181-99.

30. Moss DW, Bates TE. Activation of murine microglial cell lines by lipopolysaccharide and interferon-gamma causes NO-mediated decreases in mitochondrial and cellular function. Eur J Neurosci. 2001;13:529-38.

31. Gao K, Li X, Zhang L, Bai L, Dong W, Shi G, Xia X, Wu L. Transgenic expression of IL-33 activates CD8(+) T cells and NK cells and inhibits tumor growth and metastasis in mice. Cancer Lett. 2013;335:463-71.

32. Block ML, Zecca L, Hong JS. Microglia-mediated neurotoxicity: uncovering the molecular mechanisms. Nat Rev Neurosci. 2007;8:57-69.

33. Calabrese V, Mancuso C, Calvani M, Rizzarelli E, Butterfield DA, Stella AM. Nitric oxide in the central nervous system: neuroprotection versus neurotoxicity. Nat Rev Neurosci. 2007;8:766-75.

34. Barros VE, Ferreira BR, Livonesi M, Figueiredo LT. Cytokine and nitric oxide production by mouse macrophages infected with Brazilian flaviviruses. Rev Inst Med Trop Sao Paulo. 2009;51:141-7.

35. Murray PJ, Wynn TA. Protective and pathogenic functions of macrophage subsets. Nat Rev Immunol. 2011;11:723-37.
36. Baruch K, Kertser A, Porat Z, Schwartz M. Cerebral nitric oxide represses choroid plexus NFkappaB-dependent gateway activity for leukocyte trafficking. EMBO J. 2015:34:1816-28.

37. Shechter R, Miller O, Yovel G, Rosenzweig N, London A, Ruckh J, Kim KW, Klein E, Kalchenko V, Bendel P et al. Recruitment of beneficial M2 macrophages to injured spinal cord is orchestrated by remote brain choroid plexus. Immunity. 2013;38:555-69.

38. Franca RF, Zucoloto S, da Fonseca BA. A BALB/C mouse model shows that liver involvement in dengue disease is immune-mediated. Exp Mol Pathol. 2010;89:321-6.

39. Miller SD, Karpus WJ, Davidson TS. Experimental autoimmune encephalomyelitis in the mouse. Curr Protoc Immunol. 2010;Chapter 15:Unit 1511.

40. Paula A. Pino and Astrid E. Cardona: Isolation of brain and spinal cord mononuclear cells using percoll gradients. J Vis Exp 2011;(48):2348 doi: 10. $3791 / 2348$.

\section{Submit your next manuscript to BioMed Central and we will help you at every step:}

- We accept pre-submission inquiries

- Our selector tool helps you to find the most relevant journal

- We provide round the clock customer support

- Convenient online submission

- Thorough peer review

- Inclusion in PubMed and all major indexing services

- Maximum visibility for your research

Submit your manuscript at www.biomedcentral.com/submit
C Biomed Central 